\title{
Studies on Corrosion Behaviors of Q235 Steel Coated by the Polypyrrole Films Doped with different dopants
}

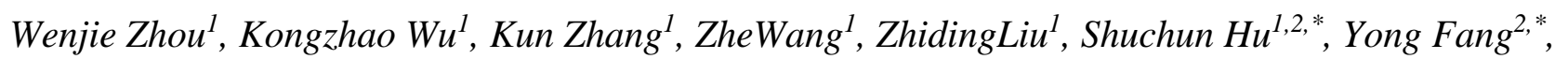 \\ Chuan $\mathrm{He}^{2}$ \\ ${ }^{1}$ Key Laboratory of Advanced Technologies of Materials (Ministry of Education), School of Materials \\ Science and Engineering, Southwest Jiaotong University, Chengdu 610031, China; \\ ${ }^{2}$ Key Laboratory of Transportation Tunnel Engineering (Ministry of Education), Southwest Jiaotong \\ University, Chengdu 610031, China.

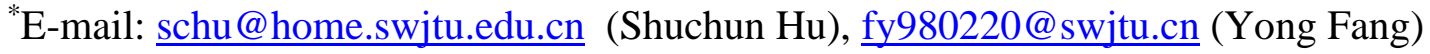

doi: $10.20964 / 2020.03 .49$

Received: 27 October 2019 / Accepted: 17 January 2020 / Published: 10 February 2020

In this paper, polypyrrole (PPy) with different dopants was prepared on the surface of Q235 steel by a potentiostatic electrochemical deposition. The doping agents were using oxalic acid (OA), p-toluene sulfonic acid (p-TSA), sulfamic acid (SA), phytic acid (PA), and sodium dodecyl benzene sulfonate (SDBS). The FT-IR analysis of the products confirmed that the above dopants were incorporated into the PPy molecular chain. SEM observation and calculation results of the void ratio for the series of products indicated that the thickness of the PPy film with different dopants was equivalent, but the SDBS-PPy film layer had the smallest aggregate particle size and the highest film density. On this basis, the research results of the dynamic potential polarization curves and electrochemical impedance spectra for the bare Q235 and the prepared series of PPy/Q235 samples (OA-PPy/Q235, p-TSA-PPy/Q235, SAPPy/Q235, PA-PPy/Q235 and SDBS-PPy/Q235) showed that the corrosion resistance of the series of PPy/Q235 samples had been significantly improved compared with the bare Q235. Furthermore, SDBSPPy/Q235 showed the best anti-corrosion performance (with the maximum $E_{\text {corr }}$, the minimum $I_{\text {corr }}$ and $\mathrm{CR}$, as well as the maximum $\mathrm{R}_{\mathrm{ct}}, \mathrm{R}_{\mathrm{po}}$ and $\mathrm{R}_{\mathrm{ox}}$ and the minimum $\mathrm{C}_{\mathrm{dl}}, \mathrm{Q}_{\mathrm{po}}$ and $\mathrm{C}_{\mathrm{ox}}$ ).

Keywords: potentiostatic; dopant; Q235; PPy; anti-corrosion performance

\section{FULL TEXT}

(C) 2020 The Authors. Published by ESG (www.electrochemsci.org). This article is an open access article distributed under the terms and conditions of the Creative Commons Attribution license (http://creativecommons.org/licenses/by/4.0/). 